\title{
SYNCHROTRON INVESTIGATION ON THE PRECIPITATION BEHAVIOUR OF NIOBIUM MICROALLOYED STEEL
}

\author{
Christian Klinkenberg ${ }^{1, a^{*}}$, Helmut Klein ${ }^{2, b}$ \\ ${ }^{1}$ SMS Siemag AG, Eduard-Schloemann-Strasse 4, 40237 Düsseldorf, Germany \\ 2 Universität Göttingen, Goldschmidtstr. 1, 37077 Göttingen, Germany \\ achristian.klinkenberg@group.com, b hklein@gwdg.de
}

Keywords: Thermomechanical processing, HSLA steel, microalloying, niobium, solubility, recrystallization, microstructure, synchrotron radiation, diffraction pattern.

\begin{abstract}
The precipitation and dissolution behavior of niobium carbo-nitrides is of particular interest for many technical applications. Niobium-microalloyed high strength low alloy (HSLA) steels are widely used in civil construction, automobile and line pipe applications. These steels rely on thermomechanical processing. In this context, coupled processes like thin slab casting and thermomechanical rolling of microalloyed steel grades require most precise information on the precipitation state at the individual processing steps.
\end{abstract}

Reasonable equations for the solubility product at thermal equilibrium can be taken from literature but kinetics is largely unknown. Conventional X-ray technology is not able to detect small volume fractions below $0.1 \%$ of nano-scale precipitates. Investigation of nano-scale niobium precipitates by transmission electron microscopy (TEM) analysis or chemical extraction methods is common practice. However, TEM suffers from statistical relevance and chemical extraction will not give information on particle distribution and orientation.

Investigation by high energy synchrotron X-ray of about $100 \mathrm{keV}$ offers statistical relevance as volumes of several cubic millimeters are regarded. This large reflecting sample volume allows to detect nanometer-sized particles and provides very high angular resolution leading to an exact determination of the reflection peaks. The wavelength of around $0.12 \AA$ is able to analyze nanometer-sized particles. Due to the high energy of the applied synchrotron radiation, precipitation and dissolution reactions could be observed during thermal treatment inside a soaking furnace. The results establish this technology for analysis of nano-scale niobium carbo-nitride precipitates

\section{Introduction}

Niobium is regarded as the most effective microalloying element, providing simultanuously high strength and toughness by grain refinement during thermomechanical processing of flat and long products. To make optimum use of the niobium potential during thermomechanical processing niobium has to be brought completely in solid solution and premature precipitation of niobium carbo-nitrides (NbC,N) has to be avoided before starting the hot forming process. However, for economic reasons the furnace temperature should be as low as possible. In the later steps of the process, Niobium remaining in solid solution after the phase transformation can contribute to strength increase by precipitation hardening of the ferrite phase [1]. Coupled processes, as thin slab casting and direct hot rolling, e.g. in a $\operatorname{CSP}^{\circledR}$ line, need special attention to adjust the corresponding process parameters [2, 3]. Other examples for typical applications of niobium metallurgy find in engineering grades as forging and spring steels [4]. Precipitation and dissolution behavior of niobium carbo-nitrides thus is of particular interest for many technical applications. 
Reasonable equations for the solubility product at thermal equilibrium can be taken from literature but kinetics is largely unknown [5]. Figure 1 gives the soluble niobium content for the alloy given in Table 1. Investigation of the nano-scaled niobium precipitates by transmission electron microscopy (TEM) analysis or chemical extraction methods is common practice [2, 6, 7]. The detection limit of niobium precipitates is about 2-3 nm [6]. Figure 2 shows finely dispersed niobium carbides that have formed in ferrite [6]. However, in situ observation of precipitate formation at processing temperature is not possible and TEM suffers from statistical relevance. Chemical extraction will not give information on particle distribution and orientation. Information on kinetics is difficult to obtain from both methods, as samples have to be quenched from soaking to room temperature. Besides the considerable experimental effort the situation at soaking temperature is evaluated from the room temperature state.

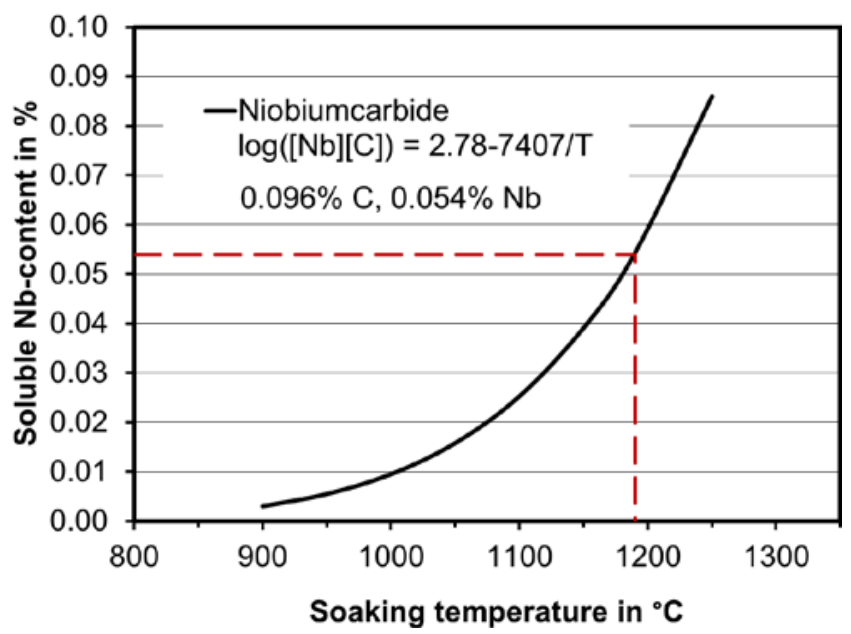

Fig. 1: Soluble Nb-content in austenite

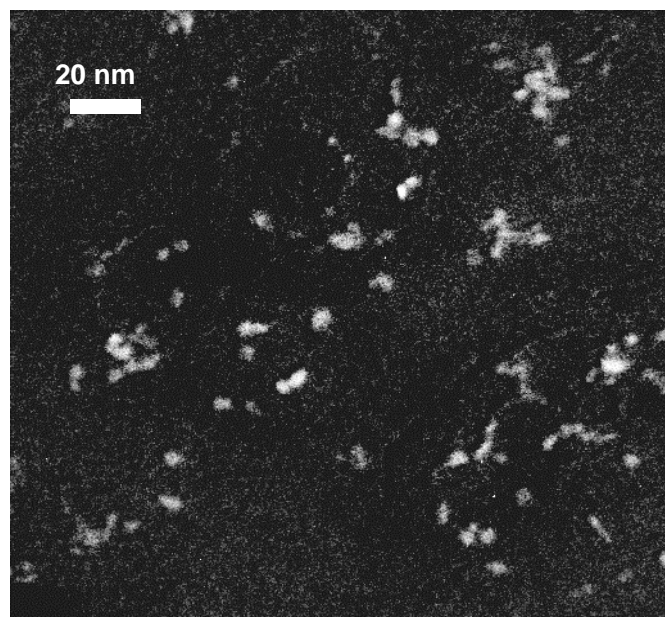

Fig 2: TEM image showing fine NbC precipitates [6]

Synchrotron radiation analysis will help to overcome these problems. Investigation by high energy synchrotron X-ray of $100-60 \mathrm{keV}(\sim 0.12-0.20 \AA)$ offers statistical relevance and a very high angular resolution power as volumes of several cubic millimeters are analyzed. In such a large irradiated sample volume even nano-particles can be analyzed. Niobium precipitates typically have diameters between $<2$ and more than $30 \mathrm{~nm}$. In addition, this technique enables in situ observation of the precipitation state as chemical composition, orientation and tilt towards the surrounding austenitic or ferritic matrix [8].

\section{Material and Experimental}

Investigated material. Chemical composition and volume percent of $\mathrm{NbC}$ of the investigated materials are given in Table 1 . The calculated volume percent of $\mathrm{NbC}$ is corresponds to complete precipitation as $\mathrm{NbC}$ and thus gives the theoretical maximum volume fraction of the investigated precipitates.

\begin{tabular}{c|c|c|c|c|c|c|c} 
Grade & $\mathbf{C}$ & $\mathbf{M n}$ & $\mathbf{N b}$ & $\mathbf{T i}$ & $\mathbf{A l}$ & $\mathbf{N}$ & $\begin{array}{c}\mathbf{v o l . \%} \\
\mathbf{N b C}\end{array}$ \\
\hline H0 & 0.080 & 0.001 & 0.052 & 0.001 & 0.002 & $<0.005$ & 0.059 \\
HSLA-HD & 0.031 & 1.5 & 0.085 & 0.01 & 0.025 & 0.004 & 0.095
\end{tabular}

Table 1: Chemical composition of investigated material in wt.-\% and calculated max. vol.- $\%$ of $\mathrm{NbC}$ 
The trials started with the model-alloy $\mathrm{H} 0$ in order to isolate the effect of the small NbC volume fraction. The more complex industrial material was examined in a second step.

Experimental. Synchrotron investigations of microalloyed steel samples have been carried out at DESY in Hamburg. The beam energy at DESY's high-energy beam-lines was $100 \mathrm{keV}$ and $60 \mathrm{keV}$ corresponding to a wavelengths of $\sim 0.12 \AA(0.012 \mathrm{~nm})$ resp. $\sim 0.20 \AA(0.002 \mathrm{~nm})$. This high-energy synchrotron radiation is in principle a very hard X-ray radiation. In contrast to conventional X-ray sources, high-energy synchrotron radiation provides a very high photon flux and a nearly perfect parallel beam in combination with low absorption. These features allow investigations of very large irradiated sample volumes $\left(\sim 10 \mathrm{~mm}^{3}\right)$ and an excellent angular resolving power of the diffracted intensities. Due to the low content of precipitates only very low diffracted intensities of the interesting carbides have been expected when compared to those of the ferrite matrix. Therefore a large irradiated sample volume and a high photon flux are necessary. An area detector owing high pixel resolution is used to record the reflected intensities in two-dimensional images. To increase the angular resolving power a sample to detector distance of $1400 \mathrm{~mm}$ was chosen. The set-up of a synchrotron beam-line is to be seen in Fig. 3 and Fig.4. The high-energy of the used synchrotronbeam allows inserting complicated sample environments, for instance vacuum furnaces or cryostats [8]. In order to understand the forming mechanism of precipitates, in-situ annealing experiments at the high-energy beam-line were carried out [9]. A halogen-lamp vacuum furnace working in the temperature range up to about $900^{\circ} \mathrm{C}$ was used (Fig. 5). The sample was annealed using a constant temperature rate of $50^{\circ} \mathrm{C} / \mathrm{min}$ under vacuum conditions of $10^{-4}$ mbar. Starting at room temperature and ending at $870^{\circ} \mathrm{C}$ diffraction images have been taken at different temperatures. Fig. 6 shows a two-dimensional diffraction image of sample $\mathrm{H} 0$ at $780^{\circ} \mathrm{C}$, displaying Debye-Scherrer-rings that are typical for the investigated materials and phases. By means of programs for quantitative phase analyses (e.g. GSAS, MAUD) it is possible to determine from such images not only the phase composition but additionally the amount of the involved phases. The broad red rings close to the black beam-stop in the middle of the figure are caused by the capton ${ }^{\circledR}$-window of the furnace. The lightly spotted Debye-Scherrer-rings indicate a grain size above $30 \mu \mathrm{m}$ of the as cast material.

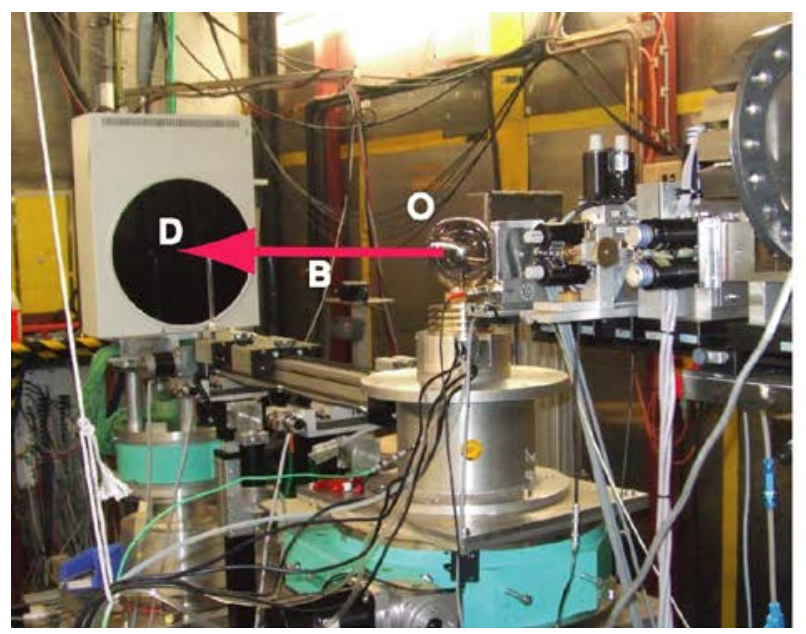

Fig. 3: Set-up of a typical high-energy beam-line at DESY (BW5), D: area-detector, O: furnace, B: primary beam

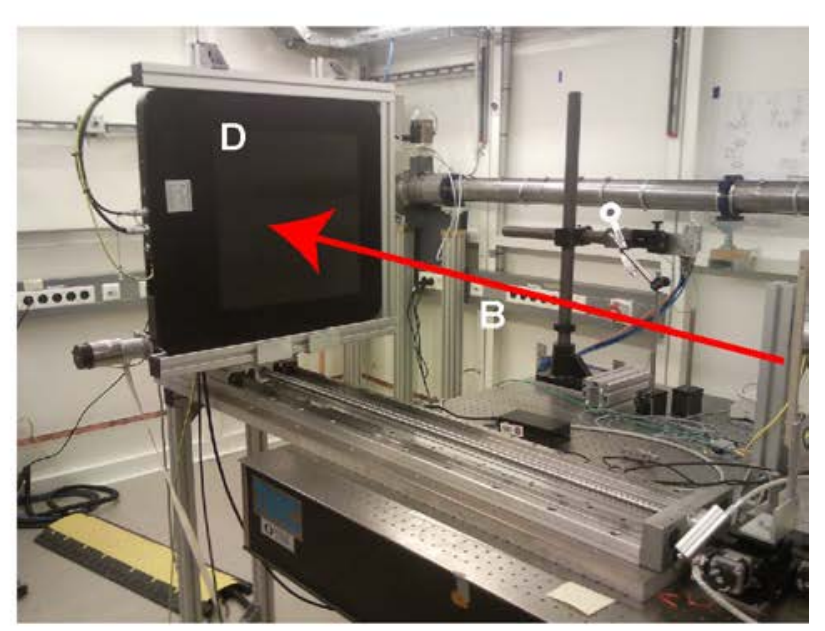

Fig. 4: Set-up of a high-energy beam-line at DESY (P02.1), D: area-detector, B: primary beam coming from halogen-lamp oven (Fig. 5a). 


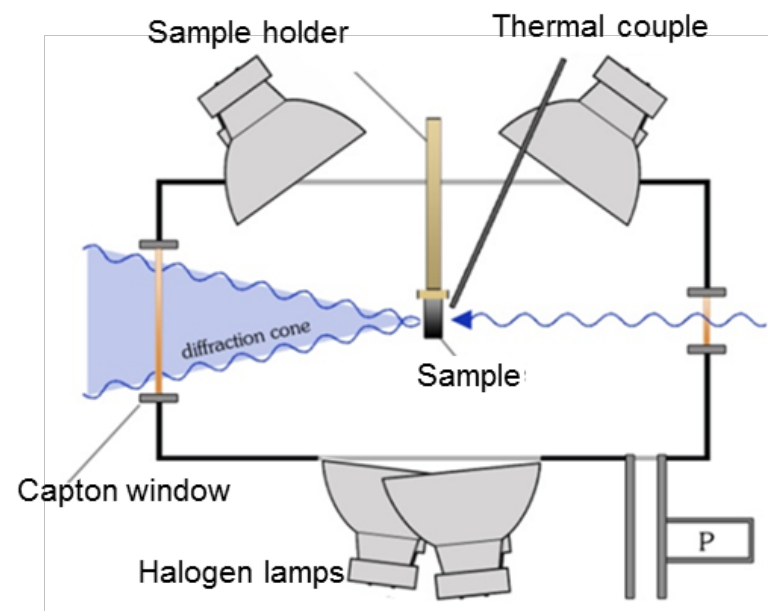

Fig. 5: Schematic view of the halogen furnace

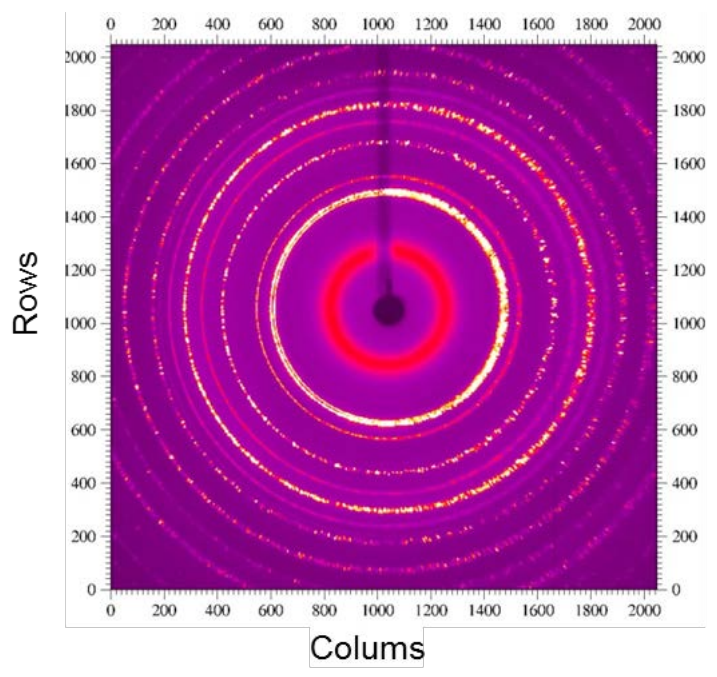

Fig. 6: Two-dimensional Debye-Scherrer diffraction image of sample $\mathrm{H} 0$ at $780^{\circ} \mathrm{C}$

\section{Experimental Results and Discussion}

Figure 6 displays the incomplete $\alpha / \gamma$ phase transformation of iron. Dissolving of $\mathrm{Fe}_{3} \mathrm{C}$ or formation of Wüstit (FeO) cannot be distinguished in this display format because of the low picture resolution. These effects can be better recognized in one-dimensional diffraction diagrams as given in Fig. 7 (measured with $60 \mathrm{keV}$ ). These diagrams are calculated from the two-dimensional images by integration over all Debye-Scherer rings.

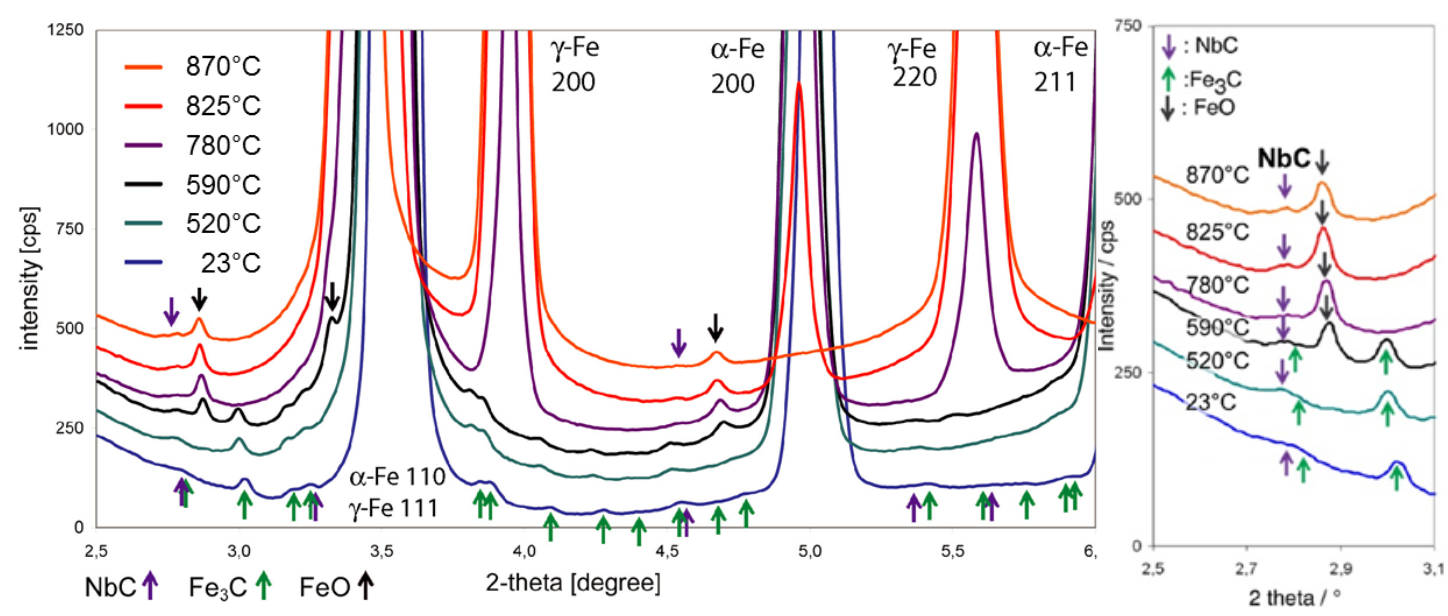

Fig. 7: a) Model alloy heated up from RT to $725^{\circ} \mathrm{C}$, b) zoom of fig. 7a at low 2-theta values

Figure 7.a shows one-dimensional diffraction diagrams of the sample as a function of the annealing temperature. Figure 7.b represents a zoom in a region between $2.5^{\circ}$ and $3.1^{\circ}$ in 2 theta. Here only the diffraction peaks of the $\mathrm{Fe}_{3} \mathrm{C}$, $\mathrm{NbC}$ and $\mathrm{FeO}$ phases appear. At about $570^{\circ} \mathrm{C} \mathrm{FeO}$ is formed and at $724^{\circ} \mathrm{C} \mathrm{Fe}_{3} \mathrm{C}$ is dissolved. $\mathrm{NbC}$ is obviously already present at room temperature. However, additional precipitation of $\mathrm{NbC}$ takes place at annealing temperature above $500^{\circ} \mathrm{C}$. This effect can be distinguished despite the low volume fraction of the precipitated NbC.

Following the investigation of model alloy H0, an industrially elaborated material has been investigated. Fig. 8 gives the one-dimensional diffraction diagram of sample HSLA-HD measured 
at room temperature with high-energy synchrotron radiation (100 keV). The diagram shows a range from $1^{\circ}-4.5^{\circ}$ in 2-theta. This region shows the interesting peaks of the precipitates numbered from $1-9$. The corresponding Bragg angles and the corresponding precipitated phases are given in Table 2. The differences between the peak positions given in Fig. 7 and Fig. 8 are caused by the different beam energy (60 keV vs. $100 \mathrm{keV}$ ).

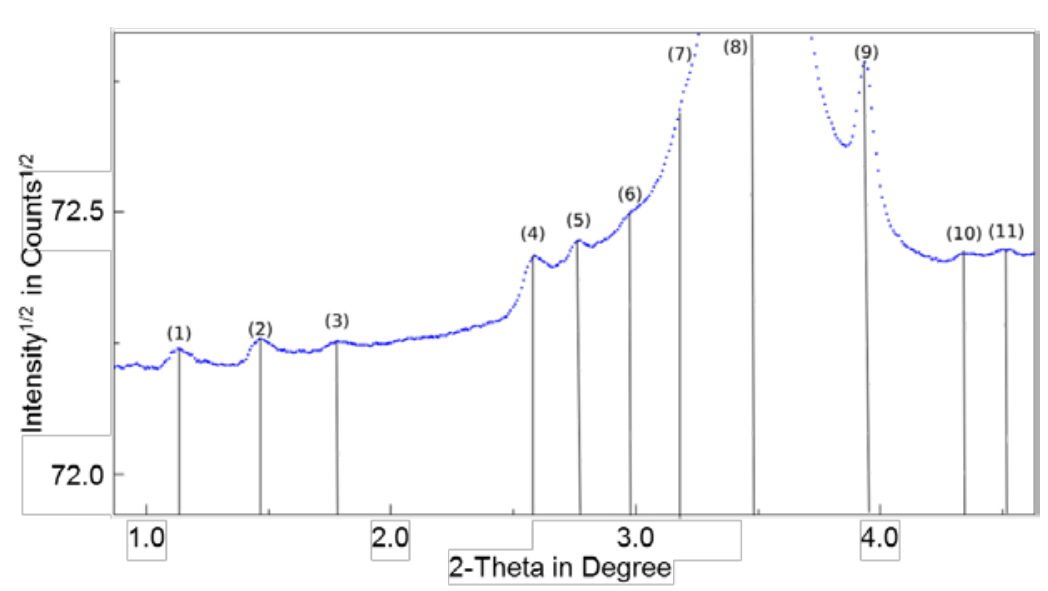

Fig. 8: One-dimensional diffraction diagram of an industrially elaborated HSLA-Steel HD. The numbers of peaks correspond to the phases given in Table 2

\begin{tabular}{c|c|c|c}
$\begin{array}{c}\text { Peak } \\
\text { No. }\end{array}$ & $\begin{array}{c}\text { 2-Theta } \\
{\left[^{\circ}\right]}\end{array}$ & Phase & $\begin{array}{c}\text { Possible } \\
\text { overlap }\end{array}$ \\
\hline 1 & 1.13 & $?$ & $?$ \\
\hline 2 & 1.46 & $\mathrm{Nb}_{2} \mathrm{C}$ & $\mathrm{Nb}_{6} \mathrm{C}_{5}$ \\
\hline 3 & 1.78 & $\mathrm{Nb}_{6} \mathrm{C}_{5}$ & \\
\hline 4 & 2.58 & $\mathrm{Nb}_{2} \mathrm{C}$ & \\
\hline 5 & 2.76 & $\mathrm{Nb}_{6} \mathrm{C}_{5}$ & $\mathrm{NbC}$ \\
\hline 6 & 3.00 & $\mathrm{Nb}_{2} \mathrm{C}$ & $\mathrm{Fe}_{3} \mathrm{C}$ \\
\hline 7 & 3.18 & $\mathrm{Nb}_{6} \mathrm{C}_{5}$ & $\mathrm{NbC}^{\circ}$ \\
\hline 8 & 3.49 & $\alpha-\mathrm{Fe}$ & \\
\hline 9 & 3.90 & $\mathrm{TiC}_{2}$ & $\mathrm{Nb}_{2} \mathrm{C}$ \\
\hline 10 & 4.35 & $\mathrm{Nb}_{6} \mathrm{C}_{5}$ & $\mathrm{Fe}_{3} \mathrm{C}$ \\
\hline 11 & 4.51 & $\mathrm{Nb}_{6} \mathrm{C}_{5}$ & $\mathrm{Nb}_{2} \mathrm{C}$
\end{tabular}

Table 2: Identified phases of precipitates of HSLA-HD in Fig. 8

When compared to model alloy H0, HSLA-HD shows multiple variations in $\mathrm{Nb}_{\mathrm{x}} \mathrm{C}_{\mathrm{y}}$-precipitate phases as $\mathrm{Nb}_{2} \mathrm{C}$ and $\mathrm{Nb}_{6} \mathrm{C}_{5}$. Besides the 110-reflection of $\alpha$-Fe and NbC-reflections, $\mathrm{Fe}_{3} \mathrm{C}$ and probably $\mathrm{TiC}_{2}$ peaks can be found.

\section{Conclusion}

The experiments show, that large irradiated sample volumes $\left(\sim 10 \mathrm{~mm}^{3}\right)$ and excellent angular resolving power of high-energy synchrotron radiation enable the identification of even small volume fractions of precipitates below $0.1 \%$.

Already at room temperature $\mathrm{Fe}_{3} \mathrm{C}$ - and $\mathrm{NbC}$-precipitates are present in the investigated alloys (Fig.7, Fig. 8). Theoretical calculations give a content of $\mathrm{Nb}$ in solid solution below $50 \mathrm{ppm}$ in the considered temperature range (Fig. 1). That is the reason why $\mathrm{NbC}$ is still stable in $\gamma$-phase of sample $\mathrm{H} 0$ during heating up to $870^{\circ} \mathrm{C}$. In this case of a clean model alloy, only NbC precipitates have been observed. The more complex industrial alloy HSLA-HD shows multiple variants of $\mathrm{Nb}_{\mathrm{x}} \mathrm{C}_{\mathrm{y}}$ phases. This is probably induced by the influence of the other alloy constituents and has been described before [6].

Further investigations will concentrate on the quantification of the precipitated Nb-phases by Reetfeld analysis [8] as well as on the simulation of industrial thermal processes. Due of the large influence of other alloy constituents on the precipitation behavior, new well defined "model" and industrial samples containing e.g. $\mathrm{Ti}, \mathrm{V}, \mathrm{Al}, \mathrm{N}$ and $\mathrm{Mn}$ in different proportions will be examined in further experiments. Also the identification of the yet unknown phases is of utmost significance. 
The authors gratefully acknowledge providing beam-time by HASYLAB / DESY.

\section{References}

[1] C. Klinkenberg, K. Hulka, W. Bleck (2004). Steel Research int. 75, pp. 744-752.

[2] M.S. Dyer, J.G. Speer, D.K. Matlock, A.J. Shutts, S.G. Jansto, K. Xu, B.G. Thomas, Microalloy Precipitation in Hot Charged Slabs, Iron \& Steel Tech., October 2010, pp. 96-105.

[3] C. Klinkenberg, C. Bilgen, J.M. Rodriguez Ibabe, B. Lopez, P. Uranga, New Trends and Technologies in Thin-Slab Direct Rolling: Improved Microstructure \& Mechanical Behaviour; in: Proc. THERMEC'2011, Québec-City, Canada, Mat. Sci. Forum Vols. 706-709 (2012), Trans Tech Publications, Switzerland, pp. 2752-2757.

[4] C. Klinkenberg, S. Trute, W. Bleck, Niobium in Engineering Steels for Automotive Applications, steel research int. 77 (2006) No. 9-10, pp. 698-703.

[5] J. Kunze, Nitrogen and Carbon in Iron and Steel Thermodynamics, Akademie-Verlag Berlin, Berlin, 1990.

[6] M. Beres, T. E. Weirich, K. Hulka and J. Mayer (2004). Steel Research int. 75, pp. 753-758.

[7] B. Soenen, S. Jacobs, C. Klinkenberg, Development of precipitation modeling tools for transfer of processing conditions to a CSP line, in: Proc. Materials Solutions Conference 7-9 October 2002, ASM International, 2002, pp. 16-24.

[8] H. Klein, Principles of Highly Resolved Determination of Texture and Microstructure using High-Energy Synchrotron Radiation, Adv. Eng. Mat. 11, 6, 2009, pp. 452-458.

[9] I. Janßen, H. Klein, C. Klinkenberg, Determination of Niobium precipitations in micro alloyed steels, Zeitschrift für Kristallographie Supplement No. 33, $21^{\text {th }}$ Annual Meeting of the German Crystallographic Society, 19-21 March 2013, Freiberg, pp. 111. 